S. O. Kravchuk, ScD, D. A. Minochkin, Ph.D

\title{
CLASSIFICATION OF HORIZONTAL TRANSMISSION SERVICE IN A MODERN CELLULAR COMMUNICATIONS SYSTEM
}

The paper discusses methods of horizontal handover in modern cellular systems, made their classification. The analysis of the basic algorithms horizontal handover, identified their advantages and disadvantages. It is shown that in spite of their large number, they all have significant drawbacks and need to be improved.

Keywords: cellular, horizontal handover.

УДК 006.91-027.21

А. О. Стопакевич, к.т.н.

Одеська наиіональна академія зв 'язку ім. О. С. Попова, м. Одеса

\section{МОДЕЛИРОВАНИЕ ПОГРЕШНОСТИ ДАТЧИКА ТЕМПЕРАТУРЫ ПРИ РАЗРАБОТКЕ ВЫСОКОТОЧНЫХ ИУС}

Решена задача моделирования случайного прочесса изменения погрешности датчика температуры при непрерывном съеме показаний в иифровой информационно-управляющей системе. На примере системы управления теплообменником показано, что учет погрешности датчика температуры при моделировании позволяет более точно оченивать качество управления.

Ключевые слова: погрешность, датчик, термометр сопротивления, моделирование, качество, система управления.

Постановка проблемы. Развитие информационно-управляющих систем (ИУС) и переход на технологию сенсорных сетей, в которых все элементы системы соединены с компьютером с помощью специального компьютерного интерфейса, не вносящего дополнительных погрешностей, ставит проблему моделирования систем, в которых необходимо производить высокоточное измерение и управление. В рамках рассматриваемой проблемы выделим задачу моделирования случайного процесса изменения погрешности датчика при непрерывном съеме показаний в цифровой системе автоматического управления (САУ). В статье решается указанная задача для САУ температуры с использованием платинового термометра сопротивления класса А.

Анализ литературы. Задача измерения температуры с помощью термометров сопротивления исследована во множестве литературных источников. В первую очередь основные требования к термометрам описаны в стандарте [1]. Далее, погрешности подробно исследованы, например, в литературных источниках [2 - 6]. Анализ литературы показывает, что, хотя погрешности датчиков в значительной степени исследованы и нормированы, моделирование случайного процесса изменения погрешности датчика в процессе непрерывного съема показаний в цифровой ИУС исследовано недостаточно.
Моделирование функционирования датчика температуры. В соответствии со стандартом [1] максимальная погрешность термометра сопротивлений определяется классом допуска. Для платинового термометра сопротивлений класса допуска $\mathrm{A}$, максимальная погрешность измерения температуры определяется по формуле:

$$
\begin{gathered}
t_{M E}= \pm(0,15+0,002|t|), \\
\text { где }|t|-\text { модуль температуры, }{ }^{\circ} \mathrm{C} ; t_{M E}-\text { мак- }
\end{gathered}
$$
симальная погрешность измерения при заданной температуре.

Погрешность измерений температуры в процессе функционирования САУ является стационарным случайным процессом с нормальным распределением вероятности. Параметрами такого случайного процесса является среднеквадратическое отклонение и математическое ожидание погрешности. Поскольку для термометра сопротивления систематическая погрешность не нормирована, математическое ожидание погрешности равно нулю. Тогда, приняв по рекомендации [7] доверительную вероятность, равную 95\%, определим, что среднеквадратическое 
отклонение погрешности $\sigma$ определяется по формуле

$$
\sigma=t_{M E} / 2,58
$$

В соответствии со стандартом [8] тепловая инерция - это величина, которая численно равна интервалу времени, по истечению которого разница между температурами среды и датчика составляет 0,368 от первоначальной разности. Тогда, моделирует инерционность датчика инерционное звено первого порядка вида

$$
W_{T S}(s)=\frac{1}{T_{T S} S+1},
$$

где $T_{T S}-$ показатель тепловой инерции.

Выберем термометр ТСП 012-011 с показателем тепловой инерции равным $15 \mathrm{c}$.

Модель блока датчика температуры для программы Matlab Simulink показана на рисунке 1.

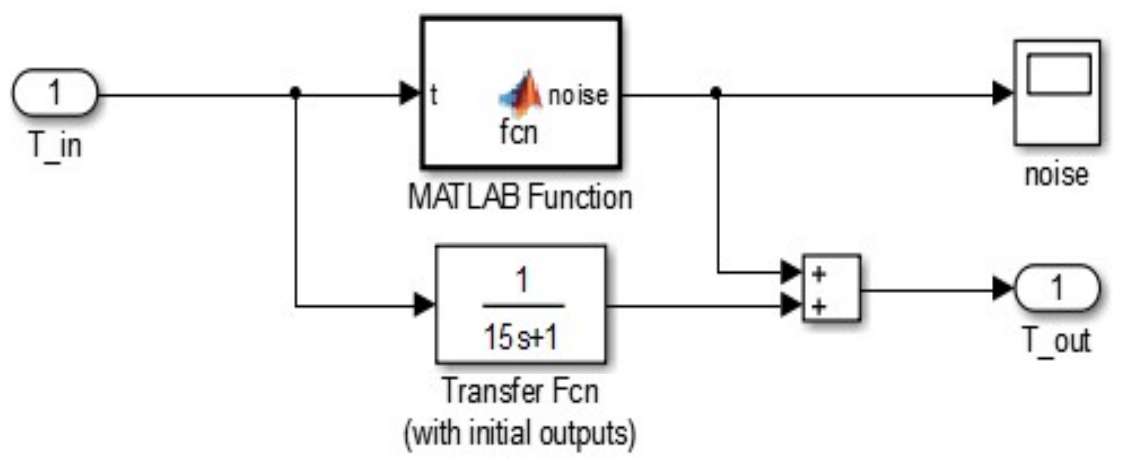

Рисунок 1 - Модель блока датчика температуры

Модель блока датчика температуры содержит два основных блока, а именно блок передаточной функции (Transfer Fcn) и блок пользовательской функции noise (MATLAB

Function). Функция noise имеет следующий вид:

function noise $=\mathrm{fcn}(\mathrm{t})$

$\mathrm{t} \mathrm{me}=0.15+0.002 * \mathrm{abs}(\mathrm{t})$;

sr_otkl=t me $/ 2.58$; noise=sr_otk1*rand $(1,1) * 2$-sr_otkl;

end

Результат моделирования погрешности выбранного термометра сопротивления в окрестности температуры $90{ }^{\circ} \mathrm{C}$ приведен на рисунке 2 .

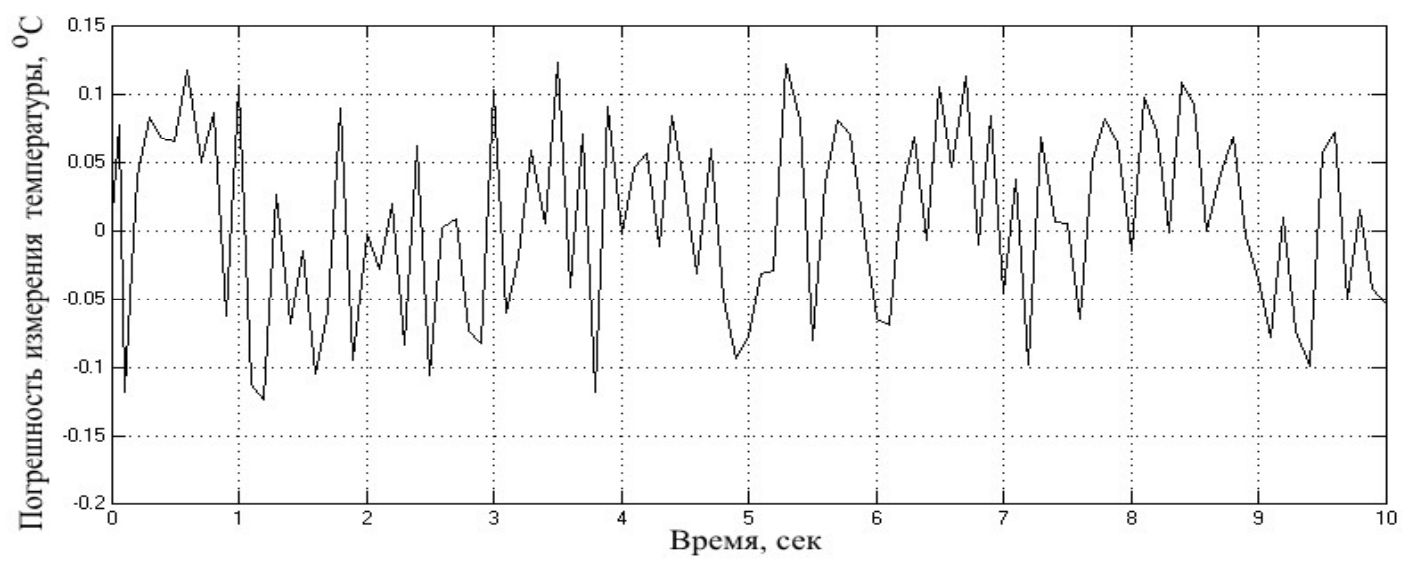

Рисунок 2 - Результаты моделирования погрешности датчика температуры

Моделирование системы управления температурой. Для исследования влияния погрешности измерений на качество функциониро вания САУ температуры, проведем моделирова ние работы системы управления парожидкостным теплообменником. Модель САУ в Matlab Simulink приведена на рисунке 3. 


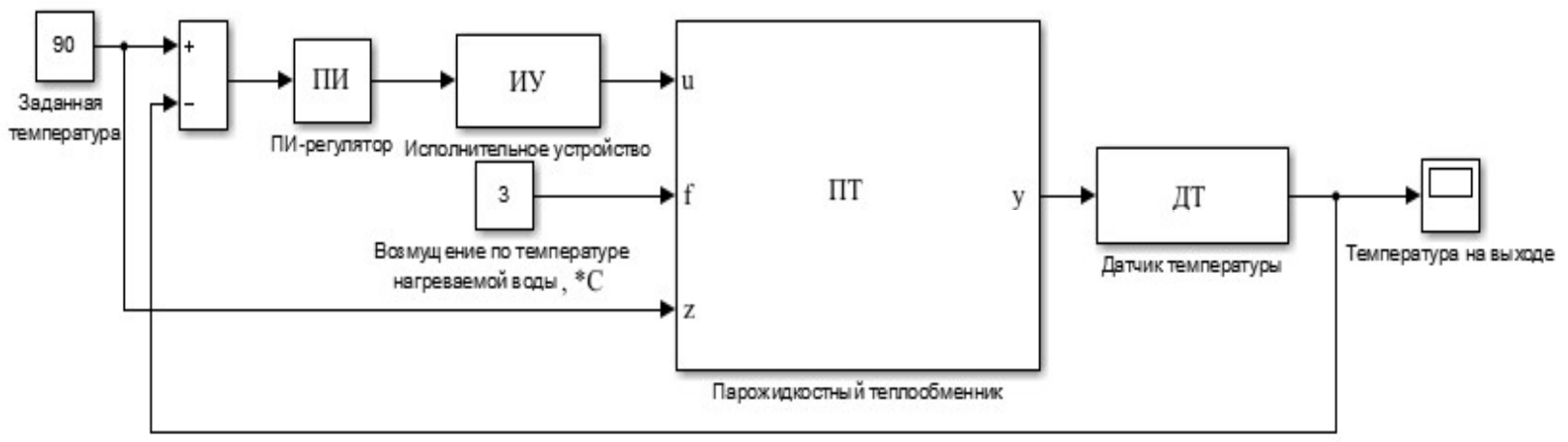

Рисунок 3 - Модель САУ температуры

Для моделирования динамики теплообменника выберем следующие условия работы: расход воды - 10 кг/с, расход пара - 0,87 кг/с, начальная температура воды $-20{ }^{\circ} \mathrm{C}$, конечная температура воды $-90{ }^{\circ} \mathrm{C}[9]$.
Результат моделирования САУ при уменьшении температуры нагреваемой воды на $3{ }^{\circ} \mathrm{C}$ с $20^{\circ} \mathrm{C}$ до $17{ }^{\circ} \mathrm{C}$, как при моделировании абсолютно точного датчика, так и датчика с погрешностью, приведен на рисунке 4.

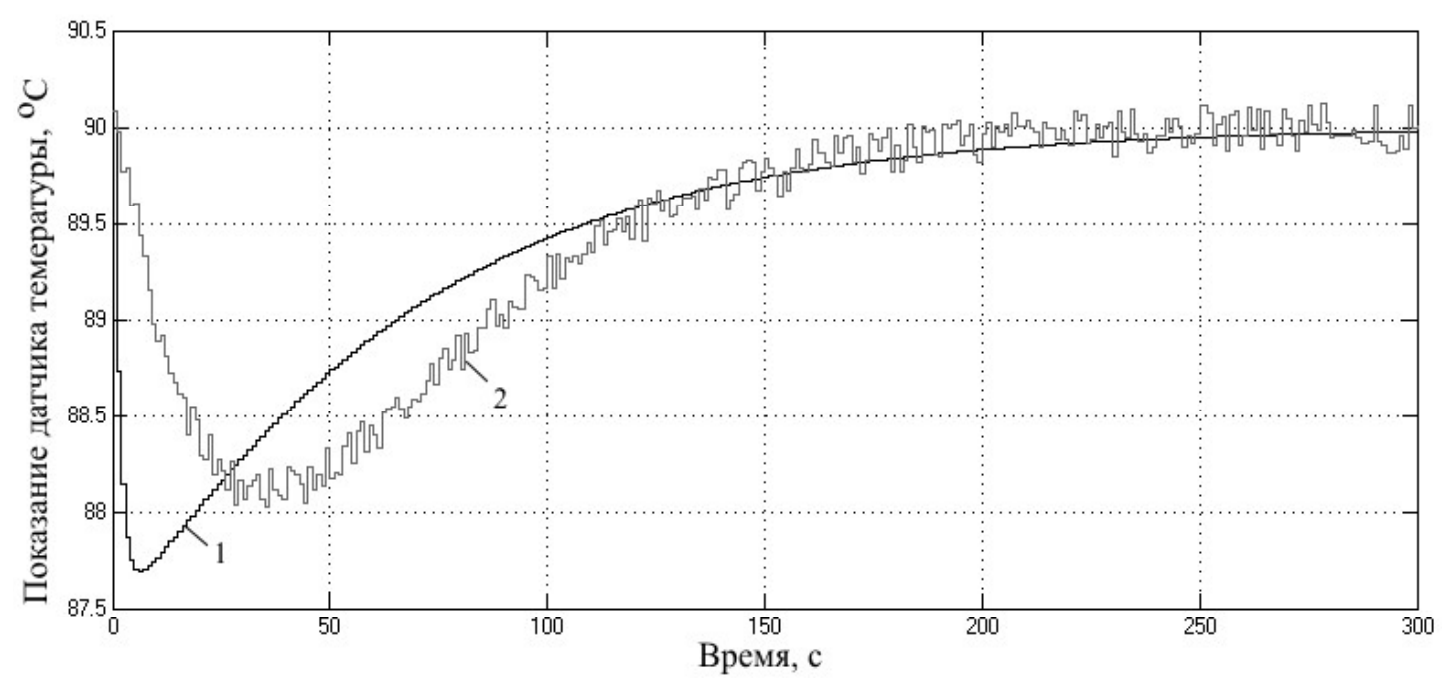

Рисунок 4 - Результаты моделирования переходных процессов в САУ: 1 - при моделировании абсолютно точного датчика; 2 - при моделировании датчика с погрешностью

\section{Выводы}

Проведено моделирование случайного процесса изменения погрешности датчика при непрерывном съеме показаний в цифровой информационно-управляющей системе. Моделирование показывает, что, например, в системе автоматического управления теплообменником учет метрологических характеристик датчика температуры и, соответственно, его модели, позволяет более точно оценить качество переходных процессов при действии возмущения или изменении задания. Процессы в системе при моделировании абсолютно точного датчика и датчика с погрешностью отличаются, особенно в области максимальных отклонений, по которым судят о качестве управления.
Перспективы исследования. При разработке современных систем управления сложными технологическими объектами большое значение имеет точность используемых математических моделей. Особенно это касается многомерных систем управления, качество работы которых во многом зависит от точности используемых математических моделей. Поэтому, моделирование метрологических характеристик распространенных в промышленности датчиков, является перспективной научной задачей. Учет погрешностей датчиков и погрешностей воспроизведения управляющих воздействий исполнительных устройств позволит повысить качество разрабатываемых современных высокоточных информационно-управляющих систем. 


\section{Список использованных источников}

1. ГОСТ 6651-2009. Термопреобразователи сопротивления из платины, меди и никеля. Общие технические требования и методы испытаний. - М: Стандартинформ, 2011.

2. Гриневич Ф. Б. Особливості та метрологічні характеристики платинових термоперетворювачів опору / Ф. Б. Гриневич, Д. В. Мелещук // Техн. електродинаміка. - 2001. - № 6. C. $66-68$.

3. Crovini R. Resistance Thermometers // Sensors. A Comprehensive Survey. Thermal Sensors. NY: VCH Publishers, 1992. - V.4. - P. 69 - 119.

4. Моисеева Н. П. Неопределенность значения температуры, измеренной платиновым термометром сопротивления / Н. П. Моисеева // Приборы. - 2002. - № 12. - С. 30 - 34 .

5. Моисеева Н. П. Выбор интерполяционного уравнения для платинового термометра сопротивления / Н. П. Моисеева // Измерительная техника. -2010 . - № 6. - С. $34-38$.

6. Yamazawa K. Improvements to the Johnson noise thermometry system for measurements at 505 800 K / K. Yamazawa, W. L. Tew, A. Pollarolo, H. Rogalla, P. D. Dresselhaus, and S. P. Benz // Tem- perature: Its Measurement and Control in Science and Industry. Proceedings of the Ninth International Temperature Symposium .- Melvile, NY: AIP Publishing, 2013. - V. 8. - P. $23-29$.

7. Новицкий П.В. Оценка погрешностей результатов измерения/ П. В. Новицкий, Н. В. Зограф. - Л.: Энергоатомиздат, 1991. $304 \mathrm{c}$.

8. ГОСТ 8.256-77. Нормирование и определение динамических характеристик аналоговых средств измерений. - М: Издательство стандартов, 1977.

9. Стопакевич А.А. Разработка модели и программных средств для создания робастной системы управления теплообменником / А. А. Стопакевич // Автоматизация технологических и бизнес-процессов. - № 7. - 2015. C. $51-61$.

Надійшла до редакиії 24.10.2015

Рецензент: д.т.н., доц. Загребнюк В. І., Одеська національна академія зв'язку ім. О. С. Попова

А. О. Стопакевич, к.т.н.

\section{МОДЕЛЮВАННЯ ПОХИБКИ ДАТЧИКА ТЕМПЕРАТУРИ ПРИ РОЗРОБЦІ ВИКОКОТОЧНИХ ІУС}

Розв'язана задача моделювання випадкового прочесу зміни похибки датчика температури при неперервному зніманні показань в цифровій інформачійно-управляючій системі. На прикладі системи управління теплообмінником показано, що врахування похибки при моделювання дозволяє більш точно очінювати якість управління.

Ключові слова: похибка, термометр опору, моделювання, якість, система управління.

A. A. Stopakevich, $\mathrm{PhD}$

\section{SIMULATION OF A THERMOMETER SENSOR IN DESIGN OF HIGN PRECISION ICS}

The resistance thermometer random process error change simulation problem with continuous metering within framework of digital information and control systems is solved. It was shown on the heat exchanger control system example that simulating with errors accounting allows to more accurately evaluate the control quality.

Keywords: error, resistance thermometer, precision modeling, quality, control system 